
AVISO: Este ficheiro pdf contém elementos multimédia e deve ser baixado e aberto FORA DO NAVEGADOR, com a versão mais recente do Adobe Reader $X$ (http://get.adobe.com/reader/).

\title{
UMA CÂMERA ENTRE BRINQUEDOS OU POR QUE PRECISAMOS DE FOTOGRAFIAS FORA DE FOCO
}

Íris Morais Araújo ${ }^{1}$

Universidade de São Paulo, São Paulo, Brasil

Apresento seis imagens que, ao serem produzidas, constituiram minha relação em campo com uma criança Karitiana de 10 anos "especial" (osikirip). Assim, chamo a atençẫo para a importância de o etnógrafo notar as distintas margens, as pessoas e os objetos que nela habitam. Essa tarefa pode revelar questóes, como a infância e a deficiência, exploradas em minha pesquisa de doutorado.

Palavras-chaves: Karitiana, fotografia, trabalho de campo, osikirip

Tive encontros imprevistos logo que cheguei, pela primeira vez, a uma das aldeias Karitiana - população Tupi-Arikém de 346 pessoas (mai. 2014) que vive concentrada principalmente em cinco aldeias localizadas nos municípios de Porto Velho e Candeias do Jamari (RO) -, em finais de julho de 2011, no papel de antropóloga colaboradora do grupo técnico da Fundação Nacional do Índio - FUNAI responsável pelos estudos de identificação e delimitação da Terra Indígena Karitiana. Quando entrei na residência onde os não indígenas ficariam hospedados, uma das esposas do dono da casa passou a me apresentar aos demais membros da família. Cumprimentei com um aceno também as crianças, que brincavam em um canto. A atitude causou risada - e, de minha parte, um constrangimento que não devo ter disfarçado muito bem - quando realizei o gesto para Timóteo (todos os nomes citados neste texto são fictícios), um dos filhos da minha anfitriã. "Ele é mudo!", alertou-me sua mãe. Com efeito, por apresentar problemas nos braços e nas pernas e não conseguir se exprimir por meio da fala - ele compreende tanto sua língua materna como o português, e se comunica com gestos e ruídos -, essa criança é referida pelos Karitiana, quando utilizam o português, como "especial". O menino aceitou a saudação e, acompanhando os outros de sua idade, saiu.

Essa menção aos "especiais" não foi um fato isolado. Ainda nas primeiras semanas de trabalho de campo, foram diversas as situações nas quais determinado interlocutor espontaneamente tocou no assunto, afirmando-me que algum parente seu era "especial" - osikirip, em sua

1 Doutora em Antropologia Social. Email: irisaraujo80@yahoo.com.br 
língua materna. Ao utilizarem tal qualificação, os Karitiana tentavam acionar a minha percepção concernente ao fenômeno da deficiência. Algo, todavia, sempre me escapava: via-me em reações desconcertadas, que demonstravam minha dificuldade para entender as explicações que me davam para certas pessoas serem chamadas de tal maneira.

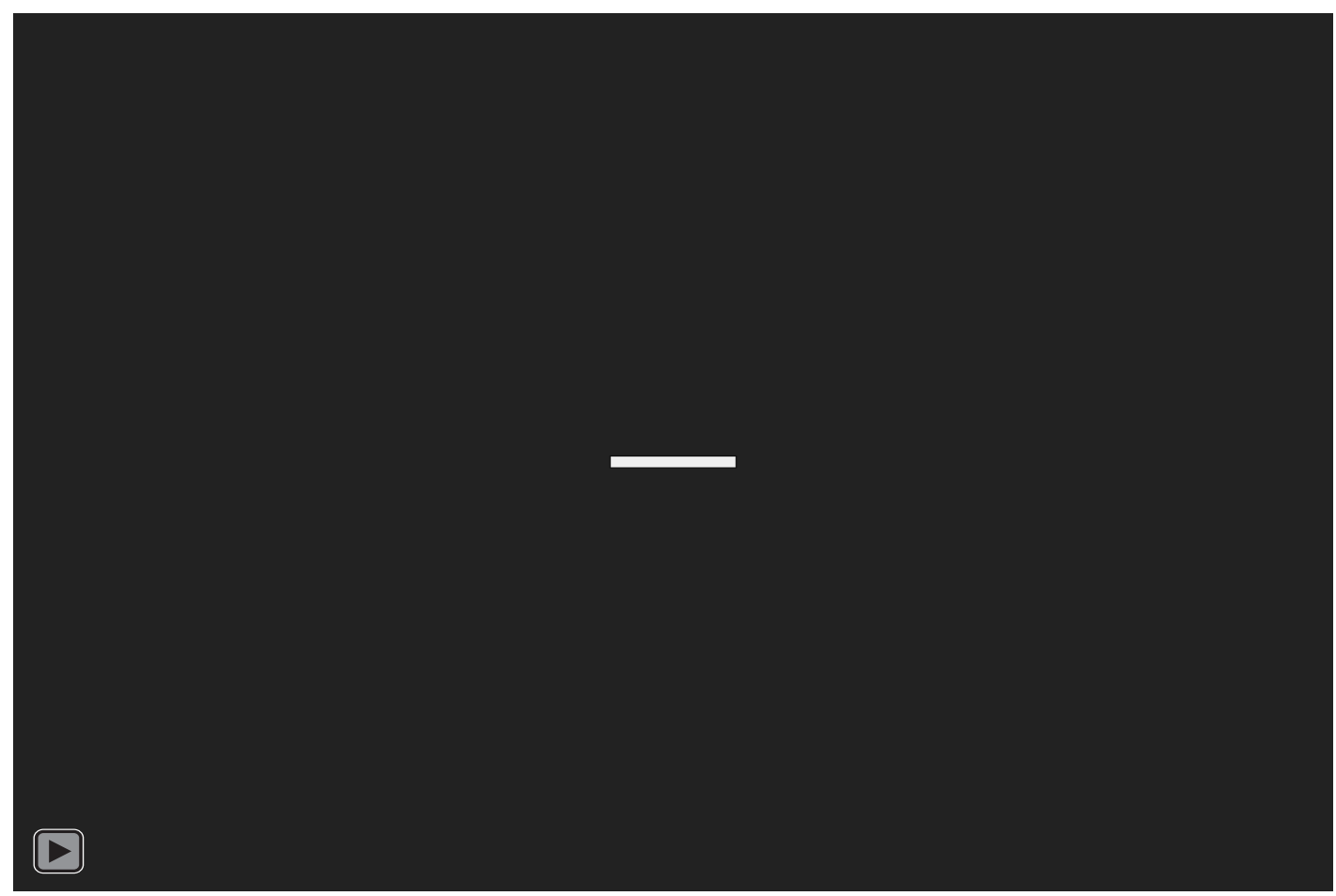

O problema, ademais, se desdobrou. Não demorei a saber que boa parte dos "especiais" são detentores do que meus anfitriões se referem como "aposentadoria". Trata-se do Benefício de Prestação Continuada - BPC, que assegura ao deficiente de baixa renda o pagamento mensal de um salário mínimo. Para usufruírem desse benefício, os Karitiana demandam, por intermédio da Secretaria Especial de Saúde Indígena - SESAI, consultas na rede pública de Porto Velho nas quais os médicos, por meio de exames específicos, podem atestar que tais pacientes são deficientes. Contudo, nesse movimento, os Karitiana não saem apenas com um laudo. $\mathrm{O}$ diagnóstico os transforma também em pacientes de terapêuticas provenientes da medicina, particularmente, de medicamentos psicotrópicos.

Procurei refletir em minha tese de doutorado (Araújo 2014) sobre essa experiência etnográfica, explorando como meus anfitriões, ao sustentarem a existência de pessoas "especiais" em diversas circunstâncias cotidianas e em contextos de acesso a políticas públicas, efetuam tal processo de diferenciação. Ao notar, para a definição dessa condição, a ênfase nas vicissitudes do corpo - falavam-me sobre problemas em braços, pernas, gargantas e cabeças, essas últimas, "doidas" - e suas disposições - a dificuldade (ou impossibilidade) de falar, comer ou aprender e a agressividade desmedida -, fiei-me na bibliografia sobre noção de pessoa ameríndia, que propõe a centralidade do "corpo como feixe de afeções e capacidades" (Viveiros de Castro 2002: 380) em contínua transformação. Conduzi a pesquisa tomando como pressuposto que meus novos amigos, ao usarem o termo "especial", não se referiam exatamente à deficiência como dispositivo não indígena. 
Sabe-se pouco sobre esse fenômeno entre populações ameríndias, de que modo sua imaginação a esse respeito pode ser pertinente para provocar tensão nas ideias às quais estamos familiarizados e enriquecendo assim os conceitos da antropologia. Arrisco-me dizer, em linhas gerais, que os Karitiana concebem os "especiais" como resultado de relações estabelecidas com meus anfitriões que produzem efeitos definhantes na capacidade da mulher em gerar um bebê. O nexo com os não indígenas é o primeiro de todos a ser enumerado. $\mathrm{O}$ aparecimento daqueles seres concebidos como os donos das armas de fogo levou os Karitiana a propor um vínculo de familiarização com os não indígenas, procurando se mostrar disponíveis a serem cuidados por esses homens poderosos. Mas, ao se disporem a ser alimentados, como bebês, pelo não indígena, alimentando-se da comida exógena oferecida por tais seres, seus corpos, antes fortes, tornaram-se débeis e suscetíveis a produzir filhos "especiais". A adesão a práticas biomédicas (como o consumo os anticoncepcionais e os tratamentos para engravidar) e a ocorrência da aids (que os Karitiana conheceram por conta das relações com não indígenas) também são explicações para a existência dessas pessoas.

Outro vínculo que meus anfitriões apontam como responsável por produzir essas pessoas é a raiva, ou falta de amor da mulher pelo marido. O casamento é entendido como um processo no qual, aos poucos, o pênis amacia a vagina, alargando-a, e é dessa maneira que o casal aprende a se gostar. É após a completa formação da mulher que ela engravida e cada filho gerado é prova do afeto de seus pais. O bebê pode nascer "especial", porém, se a esposa não aprendeu tão bem assim a gostar do marido. A mulher pode demonstrar seu afeto dando atenção, carinho e demonstrando cuidados cotidianos, como cuidar de sua casa e produzir uma boa alimentação para sua família. Por outro lado, se o marido aborrece a esposa grávida, a raiva sentida nas entranhas do corpo da gestante pode atingir a criança, que nasce "especial" por conta desse sentimento.

Há ainda o estado popopo [morto-morto], traduzido como "louco", que pode levar o Karitiana a se transformar em "especial". Quem experimenta esse estado não reconhece as pessoas, atacando-as - como o fazem os espíritos que vivem junto de meus anfitriões, nas aldeias -, pois deixa de ver o mundo da perspectiva humana e se torna kinda, um não parente predador. Para evitar que o filho fique popopo, a grávida deixa de consumir o jacu, o veado-roxo e os peixes jacundá e piau, pois são assim considerados e transmitem tal característica ao bebê. Quando nasce, os pais realizam diversos cuidados com o filho: dentre os quais, utilizam a planta pороро'аро [folha popopo], que previne esse estado.

Os Karitiana notam especificidades nos corpos de seus parentes "especiais". Cabeças, olhos, gargantas, corações, braços, rins, intestinos e pernas são inadequados, porque tortos, pequenos, abertos, fracos, finos, ausentes e assim por diante. Tais características compõem algo de repulsivo, de modo que os Karitiana ofendem essas pessoas, qualificando-as de sara, feias, erradas, ruins.

Ao corpo asqueroso, combinam-se dificuldades - falar, comer, aprender - constituintes da noção de humanidade no mundo ameríndio. Essas indisposições levam à impossibilidade de completa aquisição de linguagem e consciência que permitem a construção de relações de parentesco, cujo pressuposto é notar o eu em meio aos outros. Assim, resta aos "especiais" a raiva, forma de relação privilegiada no mundo ameríndio para lidar com o mundo exterior, mas vedada aos nexos entre iguais. Como afirmou uma amiga, seu filho "especial" parece o Amywym Huk, um dos muitos seres da floresta (como o Curupira e o Mapinguari, dentre muitos outros) que torna os caçadores "como doidos" quando o encontram, demandando tratamentos específi- 
cos para saírem desse estado. Os "especiais" se parecem com não humanos pois, como os ogros da floresta, possuem um corpo monstruoso e são potenciais agressores dos Karitiana.

Mas, ao contrário daquele que experimenta o estado popopo - que não permite distinguir os seus -, quem é "especial", ainda que crie distâncias e produza afastamentos, identifica os nexos de parentesco, sabe quem é pai, mãe, filho. Os Karitiana - particularmente suas mães, às quais cabe criar - procuram reforçar esse vínculo de todas as maneiras possíveis. Por isso, os "especiais" são incentivados a participar do cotidiano aldeão: se crianças, brincam, vão à escola, fazem pequenas tarefas; quando adultos, casam - mesmo que tenham dificuldade para criar seus filhos - e caçam - ainda que, num acesso de raiva, apontem a arma para seus próprios irmãos. O tratamento médico e o BPC são aliados do grupo, pois permitem que o "especial" conviva melhor entre os seus, usufruindo das alegrias da vida.

Se, ao longo dos oito meses de trabalho de campo, pude apreender algo da elaboração Karitiana sobre o assunto, desenhada neste ensaio em linhas muito gerais, tal período foi insuficiente para compreender bem como os próprios “especiais" elaboram a sua condição. Sobre tal tema pretendo me debruçar em pesquisas futuras. Mas já possuo algum material que me permite uma reflexão inicial sobre o assunto e é sobre ele que gostaria de tratar agora. A constituição do cotidiano com essas pessoas faz com que, ainda que sejam definidas por seus parentes pela falta - não falam, não comem, não aprendem -, os "especiais" se portam no dia a dia agenciando seus saberes e constituindo subjetividades próprias.

As fotografias que compõem este ensaio são o resultado de minha interação com um dos "especiais" com quem mais convivi e que considero o punctum da coleção de imagens que produzi até agora com meus anfitriões. Foi justamente Timóteo, o primeiro "especial" que conheci em campo, que me solicitou que as produzisse. Assim como os demais Karitiana, ele gosta muito da minha máquina, uma câmara digital das mais comuns: pede para ser retratado e adora se reconhecer (e aos seus) nas imagens quando são apresentadas como slides no computador.

Em um dia qualquer, porém, Timóteo pediu-me que eu fotografasse não ele mesmo (e abdico de mostrar essas imagens aqui em respeito aos direitos da criança e do adolescente vigentes no país), mas seus dois cavalinhos de brinquedo, um preto e outro branco. Arrumou-os de pé no chão de sua casa. Aceitei sua proposta e tirei a primeira foto, com o ângulo bem fechado. Ele foi variando as posições dos animaizinhos e assim produzi mais imagens. Esse pequeno conjunto é resultado de uma brincadeira com alguém de quem gosto muito, mas também indício de intensificação de relações que permite a ocorrência de momentos etnográficos, situações vividas no trabalho de campo que acabam por constituir problemas analíticos ao pesquisador.

Sei que essas fotos, para os cânones estéticos aos quais fomos todos educados, não são grande coisa: além da baixa resolução, o flash automático estourou as imagens. Pior ainda, algumas delas ficaram fora de foco. Nem sempre, porém, a melhor foto é a mais bonita: é indispensável tensionar as formas as quais estamos acostumados a ver para, assim, permitirmo-nos notar o que antes nos escaparia. Melhor, ainda, se nossos interlocutores de campo nos ajudarem nessa tarefa. Timóteo gostou das fotos de seus cavalinhos e alguma relevância isso parece ter. 
Não sei como meu amigo obteve seus brinquedos diletos, mas não me espantaria descobrir que ele convenceu sua mãe a adquiri-los no comércio de Porto Velho, por meio do BPC. Com efeito, para os Karitiana, toda pessoa "especial" deve gerir o benefício conforme suas necessidades e interesses. Se a família precisa do dinheiro para outros motivos, como comprar comida, deve negociar e explicar para o "especial" o motivo do uso do dinheiro para outro fim - sob pena, inclusive, de o beneficiário ficar com raiva de seus familiares.

Assim, Timóteo solicita à sua mãe roupas e brinquedos, particularmente dos seus heróis diletos, como o "Ben 10" e o "Homem-Aranha". Emival (20 anos, em 2014) sempre pede que a mãe compre iogurte, seu alimento favorito. Leonel (35 anos, em 2014) frequenta as prostitutas em Porto Velho. Violeta (45 anos, em 2014), que já foi beneficiária de um auxílio-doença, mas ainda não obteve o BPC, planeja adquirir novos utensílios domésticos para sua casa. Magali (12 anos, em 2014) adquiriu uma grande televisão de tela plana, para que sua família assistisse com conforto à Copa do Mundo, e um espaçoso armário de quarto, para que coubessem os seus pertences e os de sua irmã caçula. A criança já tinha planos para o futuro após quitar as prestações dos produtos adquiridos: comprar novas camas e colchões, para ela e sua irmãzinha. Brinquedos, roupas, prostitutas, televisão que angariam com o benefício são uma maneira de minorar a condição de "especiais", pois ficam com menos raiva, mais calmos e alegres.

Essas fotografias dos cavalinhos de Timóteo podem nos fazer recordar ainda que a Antropologia foi pensada - trabalho nosso, portanto - como ferramenta para construir argumentos que convencessem os céticos que pessoas como meu amigo, como ser humano que articula a linguagem, dá sentido ao seu mundo e pode comunicar suas experiências. $\mathrm{O}$ registro saiu tremido e isso pode ser, antes de tudo, um incentivo para tentarmos colaborar em prol da visibilidade dos cavalinhos dos outros, tantos Timóteos que existem por aí pedindo para que fotografemos seus brinquedos.

\section{REFERÊNCIAS BIBLIOGRÁFICAS}

Araújo, Íris Morais. 2014. Osikirip: os "especiais" Karitiana e a noção de pessoa ameríndia. Tese de doutorado em Antropologia Social. São Paulo: FFLCH-USP.

Viveiros de Castro, Eduardo. 2002. "Perspectivismo e multinaturalismo na América indígena." Pp. 345-399 in A inconstância da alma selvagem e outros ensaios de antropologia. São Paulo: Cosac Naify.

\section{A CAMERA BETWEen tOYS OR WHY We NEED UNFOCUSED PHOTOGRAPHS}

In this essay, I present six images which in the course of their making constituted my relationship during fieldwork with a 10 years old Karitiana Indian "special" (osikirip) child. The essay points to the importance of an ethnographer noticing the different margins, persons and objects that inhabit the ethnographic terrain. Doing so, may lead to unforeseen questions, like that of childhood and disability, as explored in my $P h D$ research.

Keywords: Karitiana, photography, fieldwork, osikirip 
Recebido em: 2015-01-30

Aceito em: 2015-03-17 